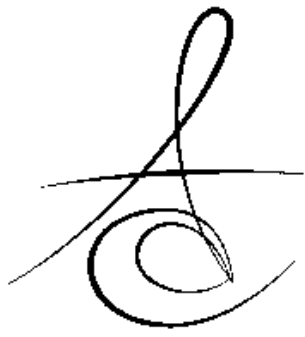

Makale Kodu/Article code: 1170

Makale Gönderilme tarihi: 06.05.2013

Kabul Tarihi: 27.06.2013

\title{
NASOPALATİN KANAL KİSTİ: BİR OLGU SUNUMU $\#$
}

\section{NASOPALATÍNE CANAL CYST: A CASE REPORT ${ }^{*}$}

\section{Doç. Dr. Binali ÇAKUR Dr.Doğan DURNA**}

\author{
Doç. Dr. Muhammet Akif SÜMBÜLLÜ* \\ Prof. Dr. Osman Murat BİLGE*
}

\section{ÖZET}

Nazopalatin kanalın embriyojenik epitelyal artıklarından meydana gelen nasopalatin kanal kisti, oral kavitede görülen en yaygın gelişimsel nonodontojenik kistlerdendir. Lezyon enfekte olmadıkça çoğunlukla asemptomatiktir ve rutin radyografik incelemede üst santral kesici dişlerin kökleri arasında sınırları düzenli radyolüsent alan şeklinde fark edilir. $\mathrm{Bu}$ vaka raporunda asemptomatik bir nazopalatin kanal kistinin ayrıntılı görüntülemesini sunmayı amaçladık.

Anahtar Kelimeler: Nazopalatin kanal kisti, non-odontojenik kist, insiziv kanal kisti

\section{ABSTRACT}

Nasopalatine duct cyst arised from embryologic epithelial remnants of nasopalatine duct is the most common non-odontogenic developmental cyst in the oral cavity. It is generally asymptomatic unless infected and is usually diagnosed as radiolucent area with irregular borders between the roots of the upper central incisors during routine radiographic examination. In this report, it is aimed to present detailed the imaging of an asymptomatic nasopalatine duct.

Key words: Nasopalatine duct cyst, nonodontogenic cyst, incisive canal cyst

\section{GİRIŞ}

Nazopalatin kanal kisti (NPKK) oral kavitenin en sık görülen gelişimsel, epitelyal, non odontojenik kistlerindendir. ${ }^{1,2}$ Nazopalatin kanal bağ ve yağ dokusu, müköz tükürük bezleri, nazopalatin arter, ven ve sinirden oluşur. ${ }^{2}$ İnsiziv kanal kisti olarak da bilinir. Nazopalatin, insiziv kanal, median palatin, palatin papilla ve median alveolar kistler, insiziv kanalla olan pozisyonlarına göre benzer lezyonun varyasyonlarıdır. ${ }^{2}$ NPKK, bazen kemik tutulumu olmadan insisiv papillada yerleşebilir ve insisiv papilla kisti adını alabilir. Maksiller anterior bölgede nazopalatin kanal içerisinde kanal artıklarından gelişen NPKK her yaşta görülebilir, ${ }^{3,4}$ fakat 4. ve 6 . dekatlarda ve erkeklerde daha sık görüldüğü bildirilmektedir.5,6 NPKK normalde enfekte olmadıkça asemptomatiktir ve genellikle rutin radyolojik incelemede iyi sınırlı, yuvarlak, oval veya kalp şeklinde radyolusent görünümü ile fark edilir. ${ }^{1,2,7}$ Çoğunlukla palatal orta hattın iki yanında ve bazen labial mukozada simetrik görülen ağrısız şişlik en sık rastlanılan bulgusudur. İlgili bölgedeki dişlerde kök rezorpsiyonu nadirdir fakat dişlerin eksen eğimlerinde sapmalara yol açabilir. Yüzeye yakın olan kistlerde fluktuasyon ve mukozada renk değişikliği görülebilir. Nazopalatin sinire bası neticesinde hissizlik veya yanma hissi oluşabilir. ${ }^{8-10}$ Kesici dişlerin apeksi hizasında, yavaş büyüyen, genellikle $1 \mathrm{~cm}$ civarında ancak daha büyük boyutlara da ulaşabilen NPKK olgularında dişler genellikle canlıdır. ${ }^{4}$ Tedavisi çoğunlukla enükleasyon, çok büyük olgularda marsupyalizasyondur. Rekürens oranı çok düşüktür ve muhtemel nedeni tamamen temizlenememesidir. ${ }^{1,2,11}$

Bu çalışmada nazopalatin kanal kistinin ayrıntılı radyolojik sunumu amaçlanmıştır.

* Atatürk Üniversitesi, Diş Hekimliği Fakültesi, Ağız, Diş ve Çene Radyolojisi Anabilim Dalı

** Serbest Diş Hekimi

"Bu çalışma oral Diagnoz ve maksillofasial radyoloji derneği V. Bilimsel sempozyumunda (33 pp., Erzurum, Türkiye, 2013) poster olarak sunulmuştur. 


\section{VAKA RAPORU}

20 yaşında erkek hasta kliniğimize dental şikâyetleri nedeni ile başvurdu. Anamnezde mevcut bir sistemik hastalığının olmadığı ve herhangi bir ilaç kullanmadığı tespit edildi. Alınan panoramik radyografide üst çenenin ön bögesinde iyi sınırlı radyolüsent bir lezyon tespit edildi (Resim 1). Yapılan ağız içi muayenesinde rafe insizivumda eksüdasyon, renk değişikliği, ödem, hiperplazi gibi herhangi bir patolojik bulguya rastlanmadı. Detaylı inceleme amacıyla konik ışınlı bilgisayarlı tomografi (KIBT) (NewTom-FP; Quantitative Radiology, Verona, Italy) çekildi. Cihaz, standart olarak $110 \mathrm{kVp}$ ve maksimum 15 mA konik ışın hüzme tekniği ile çalışmaktadır. Cihaz hastanın baş yoğunluğuna göre otomatik olarak doz seçimini sağlayan bir sisteme (AEC, automatic exposure control system) sahiptir. Cihazın gantri açısı sabit ve yere dik olduğundan, aksiyal planda KIBT incelemesi yapıldı. Aksiyal plan, hastada oksipitomeatal hatta veya sert damağa paralel alındı. Bunu sağlamak için hasta masaya sırt üstü pozisyonda yatırıldı. Bas, sert damak yere dik olacak şekilde ayarlandı. İnceleme alanı, tarama başlangıcında alınan KIBT rehber imaj üzerinden ayarlandı. KIBT inceleme $0.5 \mathrm{~mm}$ aksiyal, koronal, sagital; $0.5 \mathrm{~mm}$ crosssectional görüntüler üzerinde yapıldı. Görüntülerde insiziv kanalı içine alacak şekilde 12.17x $7.93 \mathrm{~mm}$ boyutlarında, sınırları düzenli, palatinal kemikte defekt oluşturan hipodensif litik lezyon alanı tespit edildi. İlgili bölge dişlerde yer değiştirme ve kök rezorpsiyonu mevcut değildi (Resim 2-4). Kesici dişlerinin vitalite testinde canlı oldukları görüldü. Tüm bu bulgular neticesinde lezyonun odontojenik olmadığı insiziv kanaldan kaynaklı olabileceği düşünüldü ve hastanın yapılan biyopsisinin histopatolojik incelenmesinde nazopalatin kanal kisti rapor edildi. Hasta, tedavisi için cerrahi kliniğine yönlendirildi.

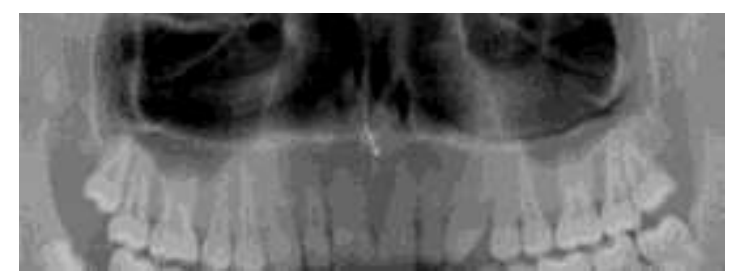

Resim 1. Panoramik filmde üst çene ön bölgede nazopalatin kanal kisti (Beyaz ok)

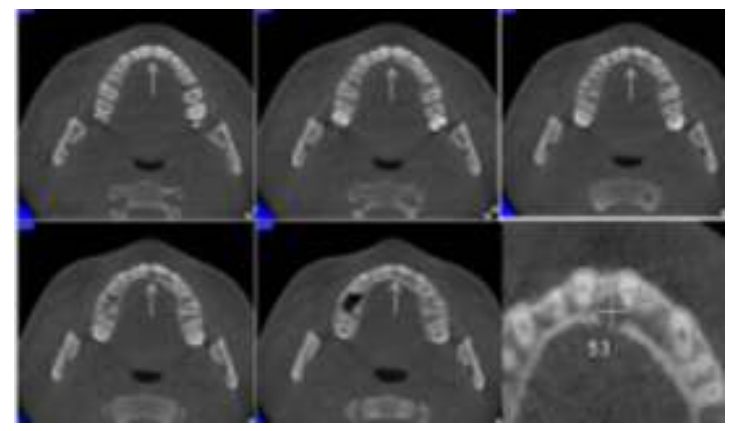

Resim 2. Nazopalatin kanal kisti aksiyel görüntüleri (Beyaz oklar).

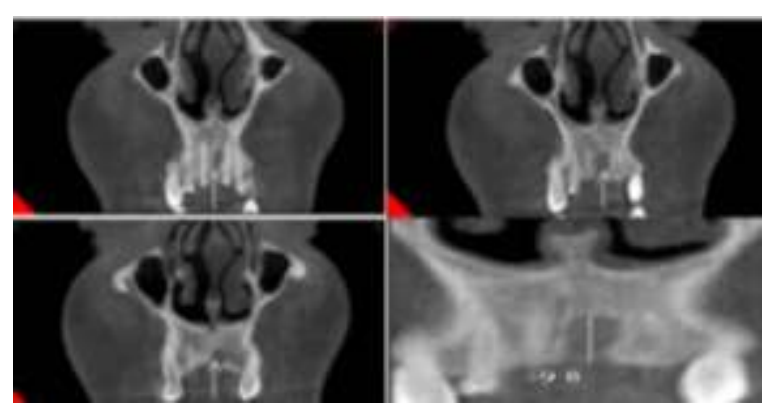

Resim 3. Nazopalatin kanal kisti koronal görüntüleri (Beyaz oklar).

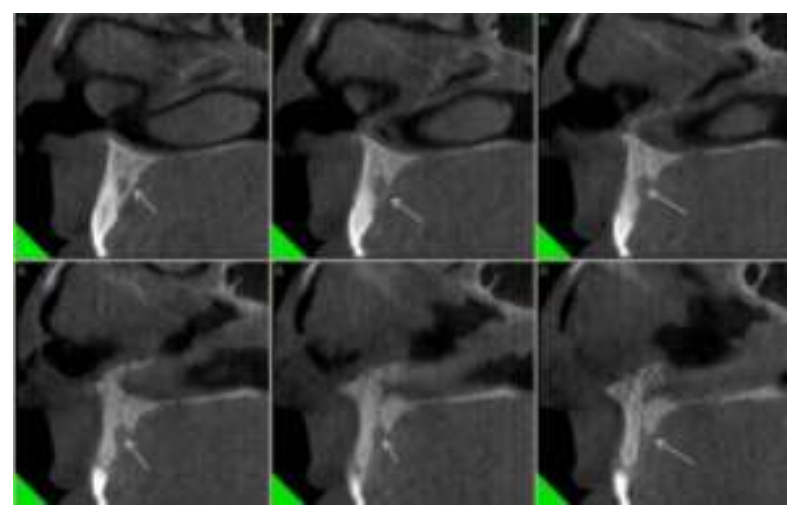

Resim 4. Nazopalatin kanal kisti sagital görüntüleri (Beyaz oklar).

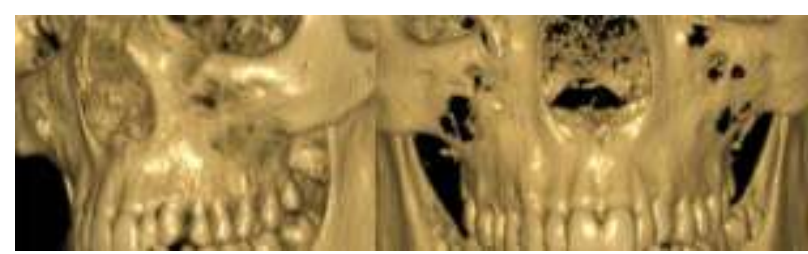

Resim 5. Nazopalatin kanal kisti 3D görüntüleri. 
Atatürk Üniv. Diş Hek. Fak. Derg.

J Dent Fac Atatürk Uni

:24, Sayı:2, Yıl: 2014, Sayfa: 258-261
ÇAKUR, SÜMBÜLLÜ; DURNA, BİLGE

\section{TARTIŞMA}

NPKK'nin embriyoda nasal ve oral kaviteler arasında bağlantı sağlayan nasopalatin kanalın embriyojenik epitel artıklarının proliferasyonu sonucu oluştuğu düşünülmektedir. ${ }^{8,9}$ Nazopalatin kanal kistinin gelişimi için gerekli stimülasyon belli değildir. Bununla birlikte travma, enfeksiyon, müköz retansiyon gibi tetikleyici faktörler bildirilmiştir fakat spontan gelişim, üzerinde en fazla durulan etyolojik faktördür. ${ }^{1,2,8,7,12}$ Sunulan vakada da hastada herhangi bir enfeksiyon bulgusu ve travma hikayesi yoktu. Kistin oluşum nedeni olarak spontan kistik dejenerasyon düşünüldü. NPKK genellikle üst ön kesici dişlerin arkasında orta hatta asemptomatik bir şişlik olarak tespit edilir. ${ }^{7,13}$ Eğer sekonder enfeksiyon gelişirse veya lokal büyüme neticesi nasopalatin sinir baskılanırsa daha sık olarak üst çene anterior palatinalde şişlik, akıntı ve ağrı görülür. ${ }^{7,8,14}$ Vakamız asemptomakti. Radyolojik olarak NPKK üst santral kesici dişlerin kökleri arasında sınırları düzenli, nazopalatin kanalı da içine alacak şekilde yuvarlak veya kalp şeklinde radyolüsent alan şeklinde görülür. Bazı kistler ise ters armut şeklindedir. 2,7,11 Radyolojik olarak oklüzal, periapikal ve panoramik gibi konvansiyonel metotlarla lezyon teşhis edilebilir fakat süperpozisyonlar nedeniyle görüntünün hekimi yanlış yönlendirebileceği unutulmamalıdır. ${ }^{2} \mathrm{Bu}$ durumu önlemek amacıyla bilgisayarlı tomografi alınabilir fakat santral dişlerin vitalitesi ile radiküler bir kist mi yoksa nazopalatin bir kist mi ayrımı yapılabilir. ${ }^{2}$ Biz vakamızı görüntülemede KIBT kullandık. Konvansiyonel tekniklere kıyasla KIBT boyut, lokalizasyon ve anatomik ilişkileri göstermede daha hassas ve kaliteli imajlar sağlamaktadır. Ayrıca, medikal BT lere kıyasla, KIBT ile klostrofobi kısmen engellenebilir, görüntüler daha az radyasyon miktarıyla elde edilebilir ve maliyeti daha ucuzdur. Ayrıca, çözünürlük daha yüksektir ve daha ince kesitler elde etmek mümkündür.

Genellikle NPKK unilateral, nadiren bilateral yerleşim gösterir. ${ }^{15}$ Yerleşim bölgesinde ki dişlerde köklerin birbirinden uzaklaşmasına sebep olabilir ayrıca nadir olarak kök rezorpsiyonu görülür. ${ }^{5}$ Radyografik olarak nasopalatin kanal kistini geniş anatomik insiziv foramenden ayırt etmek gerekir. Ayrım için radyolüsens alanın boyutuna bakılmalıdır; genellikle bu bölgedeki $6 \mathrm{~mm}$ 'ye kadar olan radyolüsens alan eğer başka klinik bulgular ya da semptomlar yok ise normal foramen için üst sınır kabul edilir. ${ }^{16}$ Ayrıca NPKK'inde ilgili dişler vital olduğu için vitalite testi yapılarak radiküler kist ve periapikal granulom ile de ayırıcı tanısının yapılması gereklidir. ${ }^{1,2,17}$ Fakat bazı büyük kistlerde, kistin Sıvı basıncına bağlı olarak dişler vitalitelerini kaybedebiecekleri unutulmamalıdır. ${ }^{2} \mathrm{Bu}$ yüzden aspirasyon tekniği ayırıcı tanıda yardımcı olmaktadır. ${ }^{1,18}$ Sunulan vakada NPKK $6.4 \times 5.3 \times 9.8$ mm boyutlarında, sınırları düzenli, palatinal kemikte defekt oluşturan hipodensif litik lezyon alanı olarak tespit edildi. İlgili bölge dişlerde yer değiştirme ve kök rezorpsiyonu mevcut değildi. Tedavisi nazopalatin kanalın içindeki damar ve sinir ile birlikte çıkartılmasıdır. Nüks nadir görülür ve \% 0-11 arasında rapor edilmiştir. 2,7,12,14

NPKK, sık karşıslaşılan bir kist olduğu için tanınması gerekir. İlgili bölgede ki dişler çoğunlukla canlıdır, bu yüzden gereksiz endodontik tedaviden kaçınılmalıdır. Bununla birlikte dişlerin devital ve köklerde rezorbsiyon olabileceği unutulmamalıdır. NPKK görüntülenmesinde CBCT kistin doğru bir şekilde yerleşimini göstermesi, boyutunun belirlenmesi ve anatomik ilişkilerin tespitinde farklı 3 boyuta ait görüntüleri ve 3D imaj oluşturma sağlaması açısından faydalı bir diagnostik metotdur.

\section{KAYNAKLAR}

1. Çetin Ö, Tekkeşin MS, Tuskan AC. Nasopalatin kanal kisti (bir olgu sunumu). İÜ Diş Hek Fak Derg 2012;46:59-64.

2. Ezirganlı Ş, Köşger HH, Kırtay M. Nazopalatin kanal kisti:bir olgu sunumu. GÜ Diş Hek Fak Derg 2010;27: 195-9.

3. Cawson RA, Odell EW. Cawson's essentials of oral pathology and oral medicine. Edinburgh: Churcill Livingston, 2008, 130-2.

4. Günhan Ö. Oral ve Maksillofasiyal Patoloji. Ankara: Atlas Kitapçılık Tic Ltd Şti, 2001, 6.

5. Elliott KA, Franzese CB, Pitman KT. Diagnosis and surgical management of nasopalatine duct cysts. Laryngoscope 2004;114: 1336-40.

6. Hegde RJ, Shetty R. Nasopalatine duct cyst. J Indian Soc Pedod- Prev Dent 2006;24: 31-2.

7. Tozoğlu S, Yolcu Ü, Yıldırım Ü, YavuzMS, Dayı E. Nasopalatin kanal kisti: iki olgu nedeniyle. Türk Oral Maksillofasial Cerrahi Derg 2007;11: 32-6. 
8. Regezi JA, Sciubba J, Jordan RCK. Oral PathologyClinical-Pathologic Correlations. Philadelphia: WB Saunders Co, 2003,256-7.

9. Neville BW, Damn DD, Allen CM, Bouquot JE. Oral and Maxillofacial Pathology. 3. bs., Missouri: Saunders, 2002, s. 28-31.

10. Staretz LR, Brada BJ, Schott TR. Well-defined radiolucent lesion in the maxillary anterior region. J Am Dent Assoc, 1990; 120: 335-6.

11. Cardesa A, Slootweg PJ. Maxillofacial Skeleton and Teeth, Slootweg PJ. Pathology of the Head and Neck. Berlin: Springer Verlag, 2006, 109.

12. Ertaş Ü, Gürbüz G, Büyükkurt C. İnsisiv kanal kisti (bir vaka nedeniyle). Atatürk Üniv Diş Hek Fak Derg 2000; 10: 89-92,.

13. Scolozzi $P$, Martinez A, Richter $M$, Lombardi T. A nasopalatine duct cyst in a 7-year-old child. Pediatr Dent 2008;30: 530-4.

14. Tanaka S, Iida S, Murakami S, Kishino M, Yamada $C$, Okura M. Extensive nasopalatine duct cyst causing nasolabial protrusion. Oral Surg Oral Med Oral Pathol Oral Radiol Endod 2008;106: 46-50,.

15. Cicciu M, Grossi GB, Borgonovo A, Santoro G, Pallotti F, Mariona C. Rare bilateral nasopalatine duct cysts: a case report. Open Dent J, 2010; 4: 812.

16. Vasconcelos RF, Ferreira de Aguiar MC, Castro WH, Cacalcanti de Araujo V, Mesquita RA. Retrospective analysis of 31 cases of nasopalatine duct cyst. Oral Dis, 1999; 5: 325-8.

17. Meyer AW. A unique supernumerary paranasal sinüs directly above the superior incisors. J Anat, 1914; 48: 118-29.

18. Berlove IJ. Anterior median palatine cyst. N Y Dent J, 1956; 16: 381-4.

\author{
Yazışma Adresi \\ Binali ÇAKUR \\ Atatürk Üniversitesi, Diş Hekimliği Fakültesi \\ Ağız, Diş ve Çene Radyolojisi \\ 25240, Erzurum, Türkiye. \\ Fax no: +904422360945 \\ Telephone : +90 4422311765 \\ E-mail: bcakur@atauni.edu.tr
}

